\title{
Project Management and Communication Software Selection Using the Weighted Regularized Hasse Method
}

\author{
Karolina Muszyńska, Jakub Swacha \\ University of Szczecin, Faculty of Economics and Management \\ ul. Mickiewicza 64, 71-101 Szczecin, Poland \\ Email: \{karolina.muszynska,jakub.swacha\}@usz.edu.pl
}

\begin{abstract}
This paper addresses the problem of selecting the most appropriate project management and communication software for a project having specific requirements. A fourstage procedure featuring the weighted regularized Hasse method is used to compare and rank the candidate tools. The ranking of the tools takes into consideration the importance of the functional and non-functional features of the project management systems with their respective weights based on the results of a questionnaire conducted among members of a dispersed international project team.
\end{abstract}

\section{INTRODUCTION}

$\mathrm{R}$ EALIZING projects in dispersed teams is a complicated and demanding task. In any project it is vital to follow a project management methodology or set of best practices to manage its different areas including scope, schedule, costs, quality and human resources. Yet, in dispersed, multinational teams, additional communication and collaboration issues may arise, as a result of linguistic problems, limited trust, scarce direct contact among team members and less influential leadership. Moreover, the physical distance in dispersed teams augments the importance of the software systems supporting project managers in planning and monitoring project progress and whole teams in communicating, collaborating and documenting the results.

The project management and communication software differs in offered features, complexity of handled information, ease of use, and price per user. Choosing one for a specific project should take into consideration its scope, size, management model, workflows and users' expectations.

With tens of available project management suites, and tens of criteria to consider, the choice of the right tool is not trivial. Moreover, such choice should be repeated for every project undertaken, as the specificity of a given project may render unusable a tool used successfully in multiple other projects. Hence the need for an easy-to-use technique capable of supporting such type of decisions.

The aim of this paper is to propose a selection procedure using the weighted regularized Hasse method [1] as an effective solution for this purpose. This method is not only

The publication was financed from the funds of the Department of Engineering of Information Systems at the Faculty of Economics and Management of University of Szczecin for maintaining research potential. simpler than the most widely used methods supporting multi-criteria decision process (such as PROMETHEE, the ELECTRE family methods, or the Analytic Hierarchy Process - see [2] for a comprehensive review), but also has a number of other benefits (primarily, highly informative and highly readable form of results - see section VI).

As a proof of concept, this method is applied to evaluate and rank project management systems with regard to the criteria and their weights defined for the case of an international project consortium, consisting of seventeen partners from eight countries. Due to its territorial dispersion and the multiplicity of communication channels among the project team members, the project represents a valid exemplification of a situation in which a deliberately selected project management and communication system is needed to ensure effective and successful project realization.

The paper is structured as follows. Section II explains the nature of issues related to project management in an international dispersed team, also stressing out the significance of the project management software. Section III provides an insight on the chosen approach, introducing the concepts of partial ordering and Hasse diagrams. Section IV provides basic information on the case project. Section V describes the applied selection procedure, whereas Section VI presents its results. Section VII concludes.

\section{PROBLEM BACKGROUND}

Realization of any kind of project in a dispersed international team is a challenging task. Different research studies show that geographic dispersion may impede effective information sharing, coordination, problem solving, building trust, and constructively resolving conflicts with others on the team $[3,4]$. Project delivery risks with distributed teams tend to be greater when compared to colocated teams [5]. This is mainly due to the lack or high limitation of face-to-face contact, which hinders interpersonal relations, trust and commitment and causes misunderstandings.

In dispersed global project teams, most communication and the building of relationships is performed through information and communication technologies (ICT), and the ICT support becomes one of critical success conditions [6].

The current trend in project management is to find technology that allows the creation of a professional 
environment for dispersed teams, similar to the one expected if these teams were collocated [7].

Project management software is a very broad category [8]. Selecting the right tool has therefore a significant effect on the success of the project and effectiveness of teamwork [9].

\section{ChOSEN METHODOLOGY}

It is a significant challenge to analyze data and make a decision taking into account many different aspects and criteria. The fact that many different indicators must be included simultaneously means that the so-called multiindicator system or multi-criteria analysis must be used [10].

One way to handle a multi-indicator system is a mathematical mapping of the single indicator values to get a one-dimensional scalar, eventually to be used as the ranking indicator [11]. However such a mapping process, e.g. by using a weighted sum, hides all background information and may also cause unwanted compensation effects [12].

There are well-known outranking methods to obtain a linear order from a multivariate data matrix [2]. A less known yet attractive alternative to the above-mentioned methods is the partial order method. It allows not only to rank objects but also to obtain information to what extent a given object is better than another.

In partial ordering, to acknowledge object $X$ as better than object $Y$ (written as: $X \geq Y$ ), there must be at least one indicator value for object $X$ which is higher than the corresponding indicator value for object $Y$, and no indicator for object $X$ is lower than the corresponding indicator value for object $Y$. If some indictors for object $X$ are higher and others are lower than the corresponding indicators of object $Y$, then the objects are recognized as incomparable. A set of comparable objects is called a chain, whereas a set of mutually incomparable objects is called an antichain. If all indicator values for two objects are equal, the objects are considered as equivalent, having the same rank [13].

Partial orders can be visualized with Hasse diagrams, in which comparable objects are connected by a sequence of lines, while incomparable objects are not connected. The levels give approximation to a weak order of the objects from "bad" (bottom) to "good" (top). Before constructing a Hasse diagram, it is essential to make sure that all indicators have a uniform orientation. Partial order method provides a weak order, where tied orders are not excluded. This is obtained by calculating the average order of the single objects, as e.g. described by Bruggemann and Annoni [14].

Partial order methodology has been used in many different research studies in environmental sciences, chemical industry, poverty analysis and many others (see [15]). It has also been successfully applied to software selection problem in the case of digital assets management systems [16].

That approach has, however, a significant weakness. In the case of problems with many criteria, such as the one researched here, often a large number of incomparabilities are observed which leads to a less meaningful representation.
Moreover, the original Hasse method considers all criteria as equally relevant in determining the final data structure, and that is not always desired. A comprehensive solution to both these shortcomings has been proposed by Grisoni et al. [1] in the form of the weighted regularized Hasse method. It is this improved method that has been chosen to solve the discussed problem. The details of the performed procedure will be provided in section $\mathrm{V}$; before that, however, the project selected for the exemplification will be described.

\section{THE CASE PROJECT}

The case project is an international cooperation project titled BalticMuseums: Love IT!, realized within the Interreg South Baltic Programme 2014-2020 and supported by the European Union from the European Regional Development Fund. The project team comprises three scientific partners, five museum or cultural institution partners and one partner specialized in creative IT-related events. Apart from the nine partners, taking part in all project activities, there are also eight associated partners, involved only in selected activities. The partners are based in eight European countries.

The main aim of the project is to develop new IT-enabled tourism products for natural and cultural heritage tourist destinations in the South Baltic Region in a form of multilingual BYOD-guided tours providing an enhanced visitor experience during and after the visit featuring multimedia content and gamification techniques.

The case project has the following characteristic properties:

- there is no single project management system used a priori by all or most of the partners (the users have different experiences and expectations);

- the partners have very different levels of IT fluency, hence the need for a very easy to use, but still highly functional solution;

- the project is scheduled for three years (there is enough time to learn the new software);

- the financial management is done in a separate system prescribed on the European Union programme level (that is why no financial features should be taken into account in the evaluation).

\section{V.SELECTION PROCEDURE}

The procedure of selecting the best project management and communication software included four stages. The first one comprised two phases - selection of criteria against which the potential project management systems will be ranked and obtaining weights reflecting the importance of each criterion. The weights were set on the basis of a questionnaire answered by the project partners' representatives. For each criterion, they were asked to assess its importance on a five grade scale. For each value on the scale, a number has been assigned: not important -0 , of little importance -1 , desired -2 , important -3 , absolutely crucial -4 . The weights of the 
respective criteria were calculated by summing up the numbers obtained from the respondents and then normalizing them to make the sum of weights of all the criteria equal to 1 .

In stage two, a set of project management systems to be evaluated was chosen. Because of the huge amount of that type of tools available, a pre-selection phase was needed. The pre-selection was based on the following assumptions: the software is recognized as popular on the benchmarking lists $[17,18]$, the annual cost of using the tool by 25 users does not exceed the threshold of 600 euro, the available disk space (in case of cloud solutions) is not less than $20 \mathrm{~GB}$, and a demo/trial version of the tool is freely available for testing.

In the third stage, the pre-selected project management tools were evaluated with Irespect to the criteria - features of the system which were defined in stage one. Fourteen of the criteria could be rated using a binary scale: with 1 assigned if a certain criterion was met, and 0 if it was not. Other criteria needed a larger evaluation scale ( 0 to 2 or even 3 ), because their scope strongly differed among the tested tools. All functions and features which were evaluated using a nonbinary scale are listed in Table I (see Table II for a full list).

As a result of stage three, the original Hasse matrix and the corresponding diagram (see Fig. 1) were obtained.

The goal of the final stage was to determine the complete ranking of the project management and communication systems for the BalticMuseums: Love IT! project team, taking into consideration the weights of the respective criteria. To accomplish that, the approach proposed by Grisoni et al. [1] was followed.

In its first phase, the weighted count matrix $t^{W}$ was obtained using the following formula [1, eq. 1]:

$$
t_{i j}^{W}=\sum_{k} w_{k} \cdot \delta_{i, j, k}
$$

TABLE I.

EVALUATION RULES FOR THE NON-BINARY FEATURES OF THE PROJECT MANAGEMENT SYSTEMS

\begin{tabular}{|c|c|}
\hline Feature (scale) & Levels (points awarded) \\
\hline sharing and co-creating docs $(0-3)$ & $\begin{array}{l}\text { no sharing/co-creating ( } 0) \text {, place to store and share files (1), place to store and share files with version control } \\
(2) \text {, sharing files and co-creating documents (3) }\end{array}$ \\
\hline email integration $(0-3)$ & $\begin{array}{l}\text { no email integration (0), notifications to external email (1), possibility to send to/receive from external email (2), } \\
\text { own mailbox/internal messages (3) }\end{array}$ \\
\hline instant messenger $(0-2)$ & no chat $(0)$, one-on-one chat $(1)$, group chat $(2)$ \\
\hline notifications $(0-2)$ & $\begin{array}{l}\text { no notifications ( } 0) \text {, automatic, but poorly configurable notifications (1), highly configurable automatic } \\
\text { notifications (2) }\end{array}$ \\
\hline project schedule $(0-2)$ & no schedule (0), schedule only defined in tasks (no visualization) (1), schedule displayed on a Gantt chart (2) \\
\hline managing tasks $(0-2)$ & $\begin{array}{l}\text { flat or two-level task hierarchy (0), at least three level tasks hierarchy (1), multilevel task hierarchy, task } \\
\text { dependencies (2) }\end{array}$ \\
\hline dashboard (0-3) & $\begin{array}{l}\text { no dashboard (0), dashboard with only recent activities (1), dashboard with tasks, activities, calendar (2), } \\
\text { dashboard with graphical visualization of project status (3) }\end{array}$ \\
\hline shared calendar $(0-2)$ & $\begin{array}{l}\text { no shared calendar }(0) \text {, calendar with no integration with external calendars (1), calendar with integration with } \\
\text { external calendars and/or meeting planner (2) }\end{array}$ \\
\hline access control $(0-2)$ & no user access management (0), basic user access management (1), advanced user access management (2) \\
\hline mobile version $(0-2)$ & no mobile app (0), basic functions mobile app (1), full mobile app (2) \\
\hline interoperability $(0-2)$ & no interoperability (0), basic export/import possibilities (1), integration with many different tools (2) \\
\hline
\end{tabular}

TABLE II.

NORMALIZED WEIGHTS OF THE PROJECT MANAGEMENT SOFTWARE EVALUATION CRITERIA

\begin{tabular}{|c|c|c|c|c|c|}
\hline Symbol & Criterion (feature of the system) & $\begin{array}{c}\text { Normalized } \\
\text { weight }\end{array}$ & Symbol & Criterion (feature of the system) & $\begin{array}{c}\text { Normalized } \\
\text { weight }\end{array}$ \\
\hline $\mathrm{C} 1$ & sharing and co-creating documents & 0.053493 & $\mathrm{C} 14$ & risks register & 0.034934 \\
\hline $\mathrm{C} 2$ & email integration & 0.063319 & $\mathrm{C} 15$ & shared calendar & 0.043668 \\
\hline $\mathrm{C} 3$ & audio/video conference & 0.040393 & $\mathrm{C} 16$ & poll option & 0.028384 \\
\hline $\mathrm{C} 4$ & discussion forum & 0.032751 & $\mathrm{C} 17$ & access control & 0.036026 \\
\hline $\mathrm{C} 5$ & instant messenger & 0.029476 & $\mathrm{C} 18$ & mobile version & 0.044760 \\
\hline C6 & notifications & 0.046943 & $\mathrm{C} 19$ & configurability & 0.031659 \\
\hline $\mathrm{C} 7$ & project schedule & 0.049127 & $\mathrm{C} 20$ & interoperability & 0.044760 \\
\hline $\mathrm{C} 8$ & managing project tasks & 0.052402 & $\mathrm{C} 21$ & ability to install on an own server & 0.025109 \\
\hline C9 & work time register & 0.037118 & $\mathrm{C} 22$ & availability of detailed documentation & 0.030568 \\
\hline $\mathrm{C} 10$ & wiki pages & 0.032751 & $\mathrm{C} 23$ & availability of tutorials & 0.045852 \\
\hline $\mathrm{C} 11$ & search engine & 0.037118 & $\mathrm{C} 24$ & helpdesk - technical support & 0.039301 \\
\hline $\mathrm{C} 12$ & dashboard & 0.046943 & $\mathrm{C} 25$ & ability to withdraw and delete data & 0.033843 \\
\hline $\mathrm{C} 13$ & issues register & 0.039301 & & & \\
\hline
\end{tabular}


where:

$$
\delta_{i, j, k}=\left\{\begin{aligned}
1 & \text { if } x_{i k} \geq x_{j k} \\
0.5 & \text { if } x_{i k}=x_{j k} \\
0 & \text { if } x_{i k} \leq x_{j k}
\end{aligned}\right.
$$

and: $w_{k}$ denotes the weight of criterion $k$, and $x_{i k}$ the evaluation of object (software system) $i$ with regard to criterion $k$.

In the second phase, a weighted regularized Hasse matrix $H^{R}$ was obtained from the weighted count matrix using the following formula [1, eq. 2$]$ :

$$
\left[H^{R}\left(t^{*}\right)\right]_{i j}=\left\{\begin{array}{cc}
1 & \text { if } t_{i j}^{W} \geq t^{*} \\
-1 & \text { if } t_{i j}^{W} \leq 1-t^{*} \\
0 & \text { otherwise }
\end{array}\right.
$$

where $t^{*}$ has been set to the minimum allowed value of 0.55 - i.e. it is enough for object $i$ to be better than object $j$ in $55 \%$ of the criteria to set an ordering between the two.

Although Grisoni et al. [1, p. 97] suggested one more phase to obtain a total ordering, in our case it was unnecessary as the chosen value of $t^{*}$ for the construction of the weighted regularized Hasse matrix was sufficient to eliminate all the incomparability between evaluated tools and to construct the complete ranking.

\section{RESEARCH FINDINGS}

The first stage of the research procedure resulted in specifying 25 criteria - features of project management tools whose importance was evaluated by the respondents of the questionnaire - the representatives of the project partner organizations. Note the simplicity of the data gathering process as compared to, e.g., the AHP method requiring pairwise comparisons [19].

Table II presents the criteria together with corresponding normalized weights (the normalization consisted in dividing each weight by the sum of all weights so that the sum of all normalized weights is 1 ). The values reflect which criteria were indicated as the most important by the majority of the respondents; the five top-ranked were: email integration, sharing and co-creating documents, managing project tasks, project schedule, and dashboard.

The second stage of the research concentrated on the preselection of project management and communication tools for the final evaluation. As a result of the pre-selection process, the following nine project management systems were chosen: Zoho Projects Premium (T1), Freedcamp Lite (T2), Moovia (T3), Proofhub Start up (T4), AdminProject (T5), Teamwork Projects Small Office (T6), Trello free (T7), 2-Plan Team free (T8) and Open Project free (T9).

In the third stage, each of the pre-selected systems was evaluated with regard to each of the 25 criteria, what resulted in creation of a source matrix for the Hasse diagram. Note that at this stage the criteria weights were not yet taken into account.

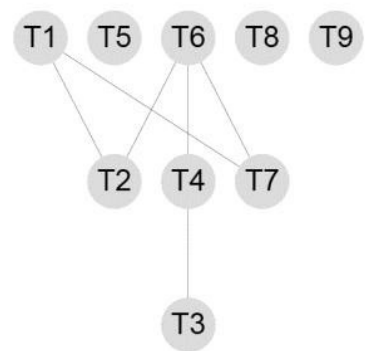

Fig. 1 The original Hasse diagram (source: own elaboration, obtained using [20]).

The Hasse diagram, presented in Fig. 1, reveals the dependences among the evaluated project management systems. There are five chains showing the order among some of the systems: $\mathrm{T} 6 \geq \mathrm{T} 4 \geq \mathrm{T} 3, \mathrm{~T} 6 \geq \mathrm{T} 7, \mathrm{~T} 6 \geq \mathrm{T} 2, \mathrm{~T} 1 \geq$ $\mathrm{T} 2$ and $\mathrm{T} 1 \geq \mathrm{T} 7$. Apart from the listed chains, other tools are incomparable with one another. Due to the existence of incomparable objects, the Hasse diagram does not provide the complete ranking of the evaluated software.

In order to accommodate the criteria weights, in the first phase of the final stage, the weighted count matrix $t^{W}$ was calculated (see Table III). The weighted count matrix was then used to calculate a weighted regularized Hasse matrix $H^{R}(0.55)$. The Hasse diagram resulting from this matrix (not presented here as it has an obvious form of a degenerate tree) revealed the complete ranking of the project management systems (see Table IV).

TABLE III

WEIGHTED COUNT MATRIX FOR THE SELECTED PROJECT MANAGEMENT TOOLS

\begin{tabular}{c|c|c|c|c|c|c|c|c|c}
\hline Project management tool & T1 & T2 & T3 & T4 & T5 & T6 & T7 & T8 & T9 \\
\hline T1 & 0.500 & 0.729 & 0.718 & 0.574 & 0.678 & 0.447 & 0.778 & 0.664 & 0.694 \\
\hline T2 & 0.271 & 0.500 & 0.570 & 0.362 & 0.553 & 0.249 & 0.585 & 0.493 & 0.538 \\
\hline T3 & 0.282 & 0.430 & 0.500 & 0.310 & 0.456 & 0.247 & 0.510 & 0.419 & 0.463 \\
\hline T4 & 0.426 & 0.638 & 0.690 & 0.500 & 0.691 & 0.373 & 0.723 & 0.632 & 0.698 \\
\hline T5 & 0.322 & 0.447 & 0.544 & 0.309 & 0.500 & 0.269 & 0.554 & 0.463 & 0.507 \\
\hline T6 & 0.553 & 0.751 & 0.753 & 0.627 & 0.731 & 0.500 & 0.800 & 0.717 & 0.716 \\
\hline T7 & 0.222 & 0.415 & 0.490 & 0.277 & 0.446 & 0.200 & 0.500 & 0.409 & 0.431 \\
\hline T9 & 0.336 & 0.507 & 0.581 & 0.368 & 0.537 & 0.283 & 0.591 & 0.500 & 0.544 \\
\hline
\end{tabular}


TABLE IV.

THE FINAL RANKING OF THE SELECTED SYSTEMS

\begin{tabular}{c|c|c}
\hline Rank & Id & Project management tool \\
\hline 1 & T6 & Teamwork Projects Small Office \\
\hline 2 & T1 & Zoho Project Premium \\
\hline 3 & T4 & Proofhub Start up \\
\hline 4 & T2 & Freedcamp Lite \\
\hline 5 & T8 & 2-Plan Team free \\
\hline 6 & T9 & Open Project free \\
\hline 7 & T5 & AdminProject \\
\hline 8 & T3 & Moovia \\
\hline 9 & T7 & Trello free \\
\hline
\end{tabular}

\section{CONCLUSION}

The selection of the most appropriate project management system is one of the most important decisions which influence the realization, communication, collaboration and documentation processes throughout the project. It is, of course, only one of many important factors which determine the success of the project, but using the right IT tools makes all other processes easier to realize.

In this paper, it was shown how the selection of the most appropriate software can be supported using a procedure consisting of four stages: (1) definition of the evaluation criteria and their importance for the project team members, (2) pre-selection of the project management software tools, (3) evaluation of the pre-selected tools against the defined criteria, and (4) establishing the complete ranking of the evaluated tools, using the weighted regularized Hasse matrix (which is much simpler than AHP or outranking methods).

The proposed procedure has been validated using the case of an international project, realized by a consortium of 17 organizations from 8 countries. The applied procedure led to the final ranking of the project management tools, listing the systems under consideration in the order of preference based on the fulfillment level of the 25 defined evaluation criteria and the criteria weights set by the consortium members.

Selection of the project management and communication software is an important element of setting up an effective project realization environment. It must be, however, taken into consideration that using even the best software tools for project management and communication is not enough to ensure project success. Appropriate procedures and processes must be defined and observed by the whole team to let the software be utilized in the best possible way [21].

It should be noted that the procedure applied in this research for evaluating and ranking the project management systems can as well be applied to other software selection problems having similar context (many candidate solutions, multiple criteria, criteria having distinct weights).

\section{REFERENCES}

[1] F. Grisoni, V. Consonni, S. Nembri, R. Todeschini, "How to weight Hasse matrices and reduce incomparabilities," Chemometrics and
Intelligent Laboratory Systems, vol. 147, pp. 95-104, 2015, http://dx.doi.org/10.1016/j.chemolab.2015.08.006

[2] M. Velasquez, P.T. Hester, "An analysis of multi-criteria decision making methods," International Journal of Operations Research, vol. 10, no. 2, pp. 56-66, 2013.

[3] N.S. Hill, K.M. Bartol, P.E., Tesluk, G.A. Langa, "Organizational context and face-to-face interaction: Influences on the development of trust and collaborative behaviors in computer-mediated groups," Organizational Behavior \& Human Decision Processes, vol. 108, no. 2, pp. 187-201, 2009, http://dx.doi.org/10.1016/j.obhdp.2008.10.002

[4] M.B. O'Leary, J.N. Cummings, "The spatial, temporal, and configurational characteristics of geographic dispersion in work terms," MIS Quarterly, vol. 31, no. 3, pp. 433-452, 2007

[5] T.U. Daim, A. Ha, S. Reutiman, B. Hughes, U. Pathak, W. Bynum, A. Bhatla, "Exploring the communication breakdown in global virtual teams," International Journal of Project Management, vol. 30, no. 2, pp. 199-212, 2012, http://dx.doi.org/10.1016/j.jproman.2011.06.004

[6] R.M. Verburg, P. Bosch-Sijtsema, M. Vartiainen, "Getting it done: Critical success factors for project managers in virtual work settings," International Journal of Project Management, vol. 31, no. 1, pp. 6879, 2013, http://dx.doi.org/10.1016/j.ijproman.2012.04.005

[7] J. Oliveira, A. Tereso, R.J. Machado, "An application to select collaborative project management software tools," in: A. Rocha, A.M. Correia, F.B. Tan, K.A. Stroetmann (eds.), New Perspectives in Information Systems and Technologies, vol. 1, pp. 467-476, Cham: Springer, 2014, http://dx.doi.org/10.1007/978-3-319-05951-8_44

[8] B. Kutlu, A. Bozanta, E. Ates, S. Erdogan, O. Gokay, N. Kan, "Project management software selection using Analytic Hierarchy Process method," International Journal of Applied Science and Technology, vol. 4, no. 6, pp. 113-119, 2014

[9] A.S.B. Ali, F.T. Anbari, "Project management software acceptance and its impact on project success," in: K. Wikstrom, K.A. Artto (eds.), Proceedings of the International Research Network on Organizing by Projects, Turku: Abo Akademi University, 2004

[10] L. Carlsen, "Data analyses by partial order methodology," Chemical Bulletin of Kazakh National University, vol. 2, pp. 22-34, 2015, http://dx.doi.org/10.15328/cb632

[11] P. Annoni, R. Bruggemann, L. Carlsen, "A multidimensional view on poverty in the European Union by partial order theory," Journal of Applied Statistics, vol. 42, no. 3, pp. 535-554, 2015, http://dx.doi.org/10.1080/02664763.2014.978269

[12] G. Munda, Social multi-criteria evaluation for a sustainable economy, Berlin: Springer-Verlag, 2008

[13] R. Bruggemann, G.P. Patil, Ranking and prioritization for multiindicator systems - introduction to partial order applications, New York: Springer, 2011

[14] R. Bruggemann, P. Annoni, "Average heights in partially ordered sets," MATCH-Communications in Mathematical and in Computer Chemistry, vol. 71, no. 1, pp. 117-142, 2014

[15] M. Fattore, R. Bruggemann (eds.), Partial Order Concepts in Applied Sciences, Cham: Springer International Publishing, 2017

[16] J. Swacha, T. Komorowski, K. Muszyńska, Z. Drążek, “Acquiring Digital Asset Management System for an International Project Consortium," Journal of Management and Finance, vol. 3, no. 1, pp. $91-102,2013$

[17] Capterra, 2016, http://www.capterra.com/project-managementsoftware/\#infographic, retrieved 5 May 2017

[18] PCMag, 2017, http://www.pcmag.com/article2/0,2817,2380448, 00.asp, retrieved 5 May 2017

[19] N. Ahmad, P. A. Laplante, "Software Project Management Tools: Making a Practical Decision Using AHP," in: 30th Annual IEEE / NASA Software Engineering Workshop, pp. 76-84, Columbia: IEEE Computer Society, 2006, http://dx.doi.org/10.1109/SEW.2006.30

[20] pyHasse online tool. http://spyout.pyhasse.org, retrieved 5 May 2017

[21] K. Muszyńska, "Project Communication Management Patterns," Annals of Computer Science and Information Systems, vol. 8 (Proceedings of the 2016 Federated Conference on Computer Science and Information Systems), pp. 1179-1188, 2016, http://dx.doi.org/10.15439/2016F235 